\title{
Ventricular size after shunting for idiopathic normal pressure hydrocephalus
}

\author{
HENRY A. SHENKIN ${ }^{1}$, JACK O. GREENBERG, \\ AND CHARLES B. GROSSMAN \\ From the Departments of Neurosurgery, Neurology, and Radiology, \\ Episcopal Hospital, Philadelphia, Pennsylvania, U.S.A.
}

SYNOPSIS It has been presumed that idiopathic normal pressure hydrocephalus is due to obstruction. We visualized the ventricles in 19 patients subsequent to shunting. We found no consistent relationship between clinical improvement after shunting and reduction in ventricular size. This suggests that the positive effect of shunting in at least some instances is due to some other factor than reduced ventricular size.

Most observers agree that a group of patients have normal pressure hydrocephalus (NPH) without obvious aetiology. All efforts to date have failed to sort out these patients accurately from other forms of senile or presenile dementia. We recently pointed out (Shenkin et al., 1973) that there were no criteria, not even isotopic cisternography, that could indicate which patients with enlarged ventricles would, or would not, respond to ventricular shunting and this is confirmed by others (Salmon, 1972; Stein and Langfitt, 1974; Wood et al., 1974). It occurred to us that one could not always be certain that the shunt was accomplishing ventricular decompression in some patients, even though it appeared to function properly with the evidence presently available - that is, the valve pumped well on manual compression, the intraventricular pressure was actually low, and an injected radioactive isotope cleared from the ventricles via the shunt. If, despite this testing, the valve were not functioning adequately, it would certainly confuse the issue and prevent any accurate evaluation of results. It was, therefore, decided to visualize the ventricles after shunting and this would give clear evidence as to whether or not the shunt was accomplishing its objective of ventricular decompression. This information

${ }_{1}^{1}$ Address for reprint requests: Dr Henry A. Shenkin, Episcopal Hospital, Front Street and Lehigh Avenue, Philadelphia, Pa. 19125, U.S.A.

(Accepted 11 March 1975.) might then be related to the clinical results achieved from operation.

\section{METHODS}

Nineteen patients, most of whom were included in our previous report (Shenkin et al., 1973), had postoperative ventriculograms performed at varying times (from seven days to three years after shunting) by direct injection of $15-20 \mathrm{ml}$ of air into the ventricles through the Rickham reservoir. This was done through a 22 gauge needle with the patient in the left recumbent position. Before the air was injected, the pressure in the right lateral ventricle was determined using a water manometer with the zero point being taken at the level of the Rickham reservoir. In all cases ventriculo-peritoneal shunts had been done using a Holter low-pressure valve that closed at a pressure between 20 and $40 \mathrm{~mm}$ of water.

The span across both lateral ventricles at the junction of the frontal horn and body was measured on frontal radiographic projection, brow-up position (Taveras and Wood, 1964). Corrections were made for differences in magnification between studies. Measurements and subjective observations of ventricular size were recorded for each case. Subjective observation by all examiners correlated well with the measured data. The following criteria for analysis of ventricular span were used: less than $40 \mathrm{~cm}$, normal; $40-45 \mathrm{~cm}$, slight enlargement; 46-55 $\mathrm{cm}$, moderate enlargement; more than $55 \mathrm{~cm}$, marked enlargement.

The measurement of the cortical mantle from the 
TABLE 1

SUMMARY OF PERTINENT OBSERVATIONS

\begin{tabular}{|c|c|c|c|c|c|c|c|c|}
\hline \multirow[t]{2}{*}{ Result } & \multirow{2}{*}{$\begin{array}{l}\text { Age } \\
(y r)\end{array}$} & \multirow{2}{*}{$\begin{array}{l}\text { Clinical } \\
\text { category }\end{array}$} & \multirow{2}{*}{$\begin{array}{c}\text { Isotope } \\
\text { cisternography }\end{array}$} & \multicolumn{2}{|c|}{$A-P$ span } & \multirow{2}{*}{$\begin{array}{c}\text { Change } \\
(\%)\end{array}$} & \multirow{2}{*}{$\begin{array}{l}\text { Ventricular } \\
\text { pressure } \\
\text { post-op. } \\
\text { (mm CSF) }\end{array}$} & \multirow{2}{*}{$\begin{array}{l}\text { Interval } \\
\text { (days) }\end{array}$} \\
\hline & & & & $\begin{array}{l}\text { Original } \\
\quad(\mathrm{mm})\end{array}$ & $\begin{array}{l}\text { Post-op. } \\
\text { (mm) }\end{array}$ & & & \\
\hline $\begin{array}{c}\text { Grade } 0 \\
\text { M.R. } \\
\text { H.P. } \\
\text { F.O. } \\
\text { J.C. } \\
\text { P.J. } \\
\text { W.J. } \\
\text { L.R. } \\
\text { L.L. } \\
\text { B.F. } \\
\text { H.K. }\end{array}$ & $\begin{array}{l}51 \\
69 \\
70 \\
51 \\
76 \\
68 \\
71 \\
76 \\
60 \\
71\end{array}$ & $\begin{array}{l}1 \\
3 \\
3 \\
1 \\
2 \\
2 \\
1 \\
1 \\
1 \\
2\end{array}$ & $\begin{array}{l}\text { Unsatisfactory } \\
\text { Positive } \\
\text { Unsatisfactory } \\
\text { Negative } \\
\text { Positive } \\
\text { Positive } \\
\text { Negative } \\
\text { Negative } \\
\text { Positive } \\
\text { Negative }\end{array}$ & $\begin{array}{l}47 \\
52 \\
41 \\
62 \\
50 \\
65 \\
49 \\
45 \\
57 \\
50\end{array}$ & $\begin{array}{l}41 \\
51 \\
38 \\
48 \\
32 \\
41 \\
48 \\
36 \\
56 \\
46\end{array}$ & $\begin{array}{r}13 \\
2 \\
7 \\
23 \\
36 \\
37 \\
2 \\
20 \\
2 \\
8\end{array}$ & $\begin{array}{r}15 \\
4 \\
90 \\
0 \\
55 \\
110 \\
12 \\
4 \\
2 \\
40\end{array}$ & $\begin{array}{r}7 \\
90 \\
35 \\
38 \\
60 \\
50 \\
25 \\
12 \\
7 \\
370\end{array}$ \\
\hline $\begin{array}{c}\text { Grade } 1 \\
\text { J.H. } \\
\text { J.W. } \\
\text { M.B. } \\
\text { L.F. } \\
\text { R.D. }\end{array}$ & $\begin{array}{l}65 \\
47 \\
75 \\
74 \\
67\end{array}$ & $\begin{array}{l}3 \\
3 \\
2 \\
2 \\
4\end{array}$ & $\begin{array}{l}\text { Not done } \\
\text { Negative } \\
\text { Negative } \\
\text { Equivocal } \\
\text { Positive }\end{array}$ & $\begin{array}{l}49 \\
56 \\
52 \\
50 \\
51\end{array}$ & $\begin{array}{l}45 \\
30 \\
49 \\
46 \\
48\end{array}$ & $\begin{array}{r}8 \\
46 \\
6 \\
8 \\
6\end{array}$ & $\begin{array}{r}6 \\
60 \\
0 \\
15 \\
34\end{array}$ & $\begin{array}{r}720 \\
360 \\
6 \\
10 \\
9\end{array}$ \\
\hline $\begin{array}{c}\text { Grade } 2 \\
\text { J.B. } \\
\text { W.B. } \\
\text { F.S. } \\
\text { C.P. }\end{array}$ & $\begin{array}{l}52 \\
66 \\
64 \\
70\end{array}$ & $\begin{array}{l}4 \\
4 \\
1 \\
2\end{array}$ & $\begin{array}{l}\text { Positive } \\
\text { Not done } \\
\text { Negative } \\
\text { Positive }\end{array}$ & $\begin{array}{l}75 \\
90 \\
60 \\
65\end{array}$ & $\begin{array}{l}45 \\
90 \\
60 \\
50\end{array}$ & $\begin{array}{r}40 \\
0 \\
0 \\
23\end{array}$ & $\begin{array}{l}10 \\
70 \\
85 \\
40\end{array}$ & $\begin{array}{r}108 \\
720 \\
540 \\
1030\end{array}$ \\
\hline
\end{tabular}

bregma to the closest border of the body of the lateral ventricle correlated poorly with the ventricular span and subjective estimation of change in ventricular size. The poor correlation was due to difficulties with correction of magnification factors and effects of slight head tilt in the lateral projection. The measurements of the cortical mantles were therefore abandoned.

Patients were graded, as before (Shenkin et al., 1973), according to the clinical results of shunting. No improvement was graded 0 . Moderate improvement, grade 1 , was judged to have occurred when the patient became more independent in daily functions, regained continence, was able to communicate needs, to feed himself, to be left alone, and was better oriented. Patients who became totally independent and capable of resuming previous responsibilities were considered to have shown an excellent response and were graded 2 . The grading system was applied rigidly and any doubt in evaluation of the patient was resolved, arbitrarily, by assignment to the next lower category. The patients were also divided according to their presenting clinical picture as previously described (Shenkin et al., 1973). The syndrome ranged from mental changes alone, category 1 , at one extreme (six cases) to disturbances confined exclusively to gait at the other end of the spectrum, category 4 (three cases). Most patients had both features in varying proportions. Category $\overline{0}$ (five cases) had primarily dementia with mild gạt disturbance, and category 3 (four cases) had gost disturbance primarily and mild dementia.

\section{RESULTS}

Table 1 summarizes all observations. Table $2 \sum^{\circ}$ shows specifically the correlation of factors of specific interest to this study. Ten patients showed no clinical response to shunting but $\stackrel{\AA}{\mathscr{}}$ nevertheless all had some reduction in ventricu- $\overrightarrow{\overrightarrow{0}}$ lar size after operation. Five of these patients 3 had what appeared to be significant reduction

TABLE 2

CORRELATION OF PERTINENT FACTORS

\begin{tabular}{|c|c|c|c|}
\hline \multirow{2}{*}{$\begin{array}{l}\text { Ventricular } \\
\text { size }\end{array}$} & \multicolumn{2}{|c|}{ Clinical response } & \multirow[t]{2}{*}{ Total } \\
\hline & + & - & \\
\hline $\begin{array}{l}\text { Decreased } \\
\text { Not decreased }\end{array}$ & $\begin{array}{l}7 \\
2\end{array}$ & $\begin{array}{l}7 \\
3\end{array}$ & $\begin{array}{r}14 \\
5\end{array}$ \\
\hline Total & 9 & 10 & 19 \\
\hline
\end{tabular}




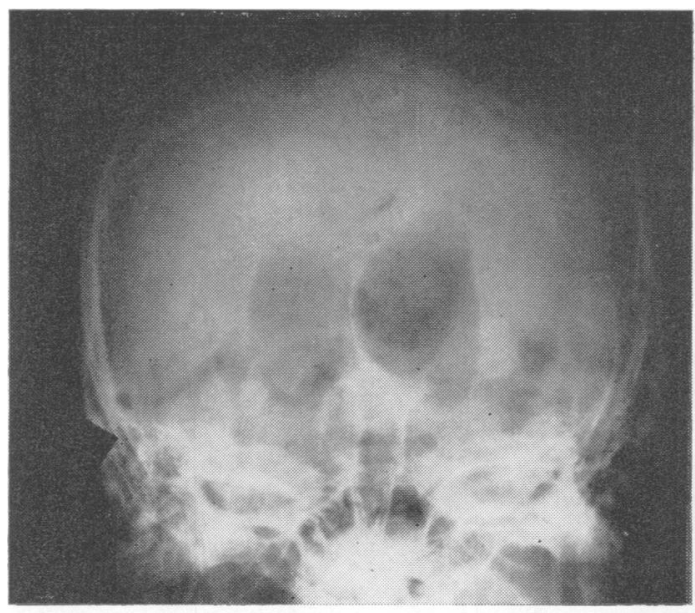

(a)

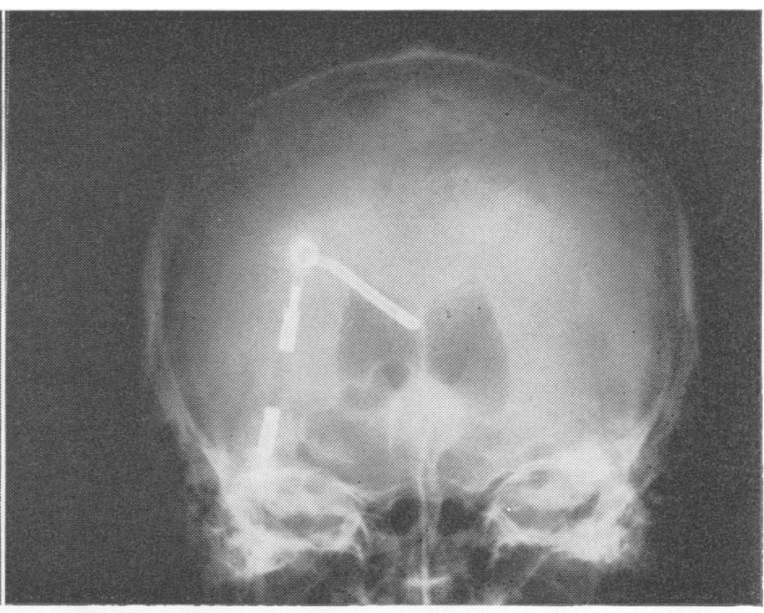

(b)

FIG. 1 W.J., no clinical response to shunting. (a) Pneumoencephalogram, anteroposterior view preoperatively. (b) Comparable view done 50 days after shunting and demonstrating a $37 \%$ reduction in size.

(more than $10 \%$ ) in ventricular size (from $13 \%$ to $37 \%$, Fig. 1). In eight of these 10 patients in the failure group dementia was the outstanding feature and in two the outstanding feature was gait disturbance. The time interval between shunt and the second air study did not appear to be a major factor (two of the patients with significant change in size had repeat air studies seven and 12 days after surgery). Four of the failure group had positive isotopic cisternograms and two of these had large decreases in ventricular size, each greater than $35 \%$.

In the grade 1 patients (moderate response) four of five had a mild change in ventricular size, and only one had a truly large decrease $(45 \%)$. The decrease in the others ranged from $6 \%$ to $8 \%$.

In the grade 2 patients (excellent response) two showed a significant change in size $(40 \%$ and $23 \%$ smaller) but, surprisingly, in the other two in this group there was no change in ventricular size. Of nine patients in the combined grades 1 and 2 , seven had isotopic cisternograms; only three of these had a positive test and one was equivocal. Eight of nine patients in the combined grades 1 and 2 had a gait disorder either solely or in combination with dementia. The longest intervals between shunt and repeat air studies occurred in six patients (one to three years) all of whom had shown improvement (grades 1 and 2) and two of these had no change at all in ventricular size, one had a modest decrease, and three had sizeable decreases in ventricular volume.

The anteroposterior (AP) ventricular span decreased to normal in four patients, preoperatively. One of these (J.W.) had marked dilatation, two were classified as having moderately dilated ventricles and one recovered to normal from only a mild degree of ventricular enlargement. With respect to the eight patients who preoperatively were classified as having marked ventricular enlargement, after shunting three had no change, two reduced to moderate dilatation, two to mild enlargement, and one returned to normal.

The intraventricular pressures measured just before introduction of the air through the Rickham reservoir were generally low. In 15 of the 19 patients the pressures were below $60 \mathrm{~mm}$ of water and in the remaining four the highest pressure was $110 \mathrm{~mm}$ of water. Of these highest four, two patients had no decrease in size of their ventricles, but were excellent results and two were poor results with one having a $37 \%$ reduction in ventricular size and the other a $7 \%$ reduction. 


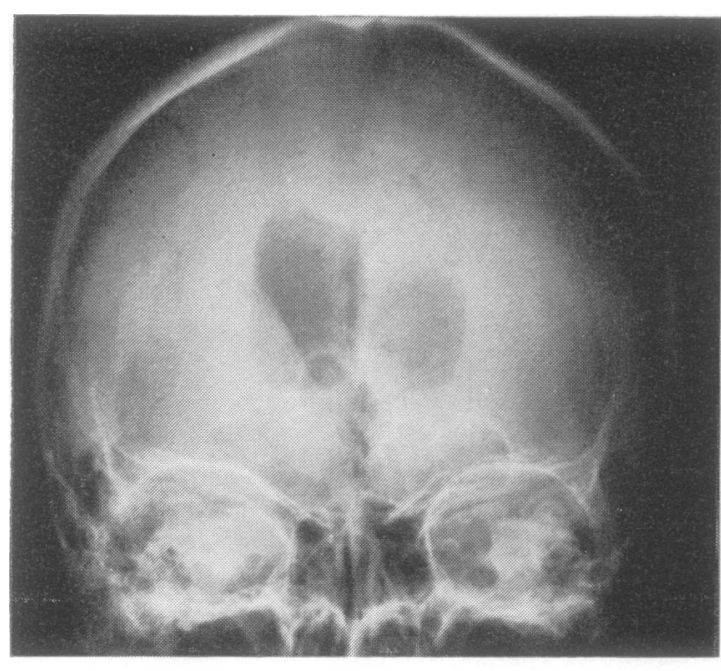

(a)

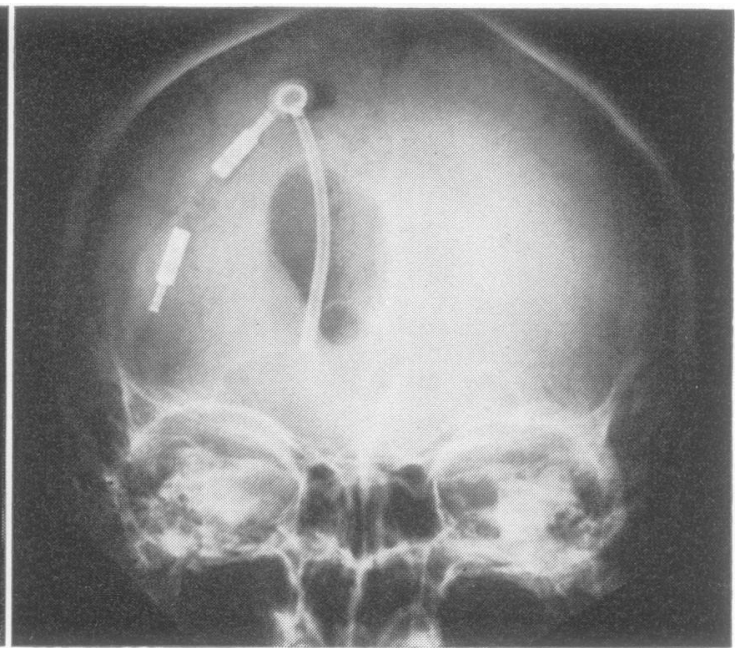

(b)

FIG. 2 F.S., remarkable clinical recovery postoperatively. (a) Pneumoencephalogram, anteroposterior view $\omega_{\infty}^{\dot{\omega}}$ preoperatively. (b) Comparable view done 540 days postoperatively; no change in size can be seen despite 0 visualization only of right lateral ventricle.

\section{DISCUSSION}

The clear implication from this study is that overall there is no relationship between clinical improvement after shunting and whether (or to what degree) reduction of ventricular size occurs in patients with idiopathic normal pressure hydrocephalus. Consequently, we must believe that in a significant number of patients with a clinical picture compatible with this diagnosis, the obstructive factor as reflected in ventricular size may not be critical.

If the obstructive factor is not critical in a significant portion of patients with idiopathic normal pressure hydrocephalus, previous efforts to distinguish that disorder from other forms of senile dementia on the basis of tests to determine the presence or absence of obstruction in cerebrospinal fluid absorption cannot always be relied upon. This is confirmed by analysis of several series of cases which failed to find a consistent correlation between the results of ventricular shunting and tests designed to determine the presence of interference with cerebrospinal fluid circulation and absorption (Salmon, 1972; Shenkin et al., 1973; Wolinsky et al., 1973;
Siegel and Johnson, 1974; Stein and Langfitt 1974; Wood et al., 1974).

The patients who had a dramatic response to shunting without any decrease in ventricula size, even up to two years after operation, pro- $\varphi$ vide the clearest indication that a process other than a purely obstructive one must be operative. The following case illustrates this point:

F.S., a 64 year old white female, had a six month history of severe progressive dementia including urinary incontinence but no gait disturbance. An air study revealed markedly enlarged ventricles (Fig. 2a) and in spite of a negative isotopic cisternogram, a ventriculo-peritoneal shunt was done. Six weeks later, she was normal. Formal psychological testing revealed an increase in overall IQ from 79 to 91 . She was last seen two years later and her recovery was maintained. Repeat air study revealed no decrease in ventricular size (Fig. 2b).

If it is not relief of an obstructive process that has produced improvement in this and similar instances, perhaps in some way drainage of spinal fluid away from its natural pathway altered the disease on a biochemical basis. $A_{N}$ recent publication indicates that, indeed, in $\sigma$ senile dementia there is a distinct alteration in 
the biochemical content of the brain (Bowen et al., 1973). Furthermore, this experience, and several others, is contrary to the report of Messert and Wannamaker (1974) that dementia must be mild to respond to shunting.

On the other hand, it cannot be concluded that obstruction to the circulation of CSF is not an aetiological factor in some patients with idiopathic normal pressure hydrocephalus. We have in the present report several patients with large ventricular dilatations and positive evidence of interference with CSF absorption on isotopic testing who have had sizeable reduction in ventricular size and excellent clinical results on shunting. Indeed, we are impressed with the predictability with which good effects of ventricular shunting will occur in patients with marked gait disturbance, little or no dementia, and truly enlarged ('ballooned' or 'rounded') ventricles. We reported this in our original series and it continues to be our experience. This should undoubtedly give credence to the possibility that at least a segment of the idiopathic normal pressure hydrocephaly group is purely obstructive in nature. But, again, even this picture is clouded. One of our finest results is a patient with marked gait disorder and no dementia and enormously ballooned ventricles who has remained improved for more than two years and who did not have any reduction in ventricular size! A further problem is that severe communicating hydrocephalus can occur without symptoms (McHugh, 1964; Luzecky et al., 1974); it is therefore not clear why patients in this and other reports have symptoms even with relatively mild ventricular enlargement. This further suggests that parenchymal disease of the brain may be a key factor even in this probably obstructive portion of the idiopathic group of normal pressure hydrocephalus.

Our hypothesis that poor valve function in some instances might be responsible for the unpredictability of results has been disproven. Certainly the majority of patients (14 of 19) had reduced ventricular size after shunting. Of the remaining five patients, two had excellent results despite failure of reduction of ventricular size. There are then only three patients in whom the possibility remains that failure of significant reduction in ventricular size and lack of clinical improvement from shunting could be due to inadequate valve function. However, the very low intraventricular pressures recorded in each of these patients does point to probable adequate valve function. Further, the fact that seven other patients in this group (grade 0 -Table 1) had no clinical response despite adequate ventricular decompression and others with good clinical improvement without reduction of ventricular size makes it unlikely that inadequate valve function is a major factor in our inability to predict results from shunting in these patients.

\section{REFERENCES}

Bowen, D. M., Smith, C. B., and Davison, A. N. (1973) Molecular changes in senile dementia. Brain, 96, 849-856.

Luzecky, M., Siegel, B. A., Coxe, W. S., and Berg, L. (1974). Papilledema and communicating hydrocephalus. Archives of Neurology, 30, 487-489.

McHugh, P. R. (1964). Occult hydrocephalus. Quarterly Journal of Medicine, 33, 297-308.

Messert, B., and Wannamaker, B. B. (1974). Reappraisal of the adult occult hydrocephalus syndrome. Neurology (Minneap.), 24, 224-231.

Salmon, J. H. (1972). Adult hydrocephalus. Evaluation of shunt therapy in 80 patients. Journal of Neurosurgery, 37, 423-428.

Shenkin, H. A., Greenberg, J., Bouzarth, W. F., Gutterman, P., and Morales, J. O. (1973). Ventricular shunting for relief of senile symptoms. Journal of the American Medical Association, 225, 1486-1489.

Siegel, B. A., and Johnson, E. W. (1974). Measurement of intrathecal $\mathrm{I}^{131}$-albumin transport to plasma. Neurology (Minneap.), 24, 501-503.

Stein, S. C., and Langfitt, T. W. (1974). Normal-pressure hydrocephalus. Predicting the results of cerebrospinal fluid shunting. Journal of Neurosurgery, 41, 463-470.

Taveras, J. M., and Wood, E. H. (1964). Diagnostic Neuroradiology, p. 284. Williams and Wilkins: Baltimore.

Wolinsky, J. S., Barnes, B. D., and Margolis, M. T. (1973). Diagnostic tests in normal pressure hydrocephalus. Neurology (Minneap.), 23, 706-713.

Wood, J. H., Bartlet, D., James, A. E., Jr, and Udvarhelyi, G. B. (1974). Normal-pressure hydrocephalus: diagnosis and patient selection for shunt surgery. Neurology (Minneap.), 24, 517-526. 